\title{
Dualism Revisited: Body vs. Mind vs. Soul
}

\author{
Rebekah A. Richert ${ }^{\mathrm{a}, *}$ \\ Paul L. Harris ${ }^{\mathrm{b}}$ \\ ${ }^{a}$ Department of Psychology, University of California, 900 University Avenue, \\ Riverside, CA 92521, USA \\ ${ }^{\mathrm{b}}$ Harvard University, Cambridge, MA, USA \\ *Corresponding author, e-mail: rebekah.richert@ucr.edu
}

\begin{abstract}
A large, diverse sample of adults was interviewed about their conception of the ontological and functional properties of the mind as compared to the soul. The existence of the mind was generally tied to the human lifecycle of conception, birth, growth and death, and was primarily associated with cognitive as opposed to spiritual functions. In contrast, the existence of the soul was less systematically tied to the lifecycle and frequently associated with spiritual as opposed to cognitive functions. Participants were also asked about three ethical issues: stem cell research, life support for patients in a persistent vegetative state and cloning. As expected, participants' beliefs about the ontology and function of the soul were linked to their judgments about these ethical issues whereas their beliefs about the mind were unrelated. Overall, the findings show that many adults do not espouse a simple body-mind dualism, and any tendency toward such dualism is unlikely to explain their beliefs in an afterlife. Instead, afterlife beliefs appear to be associated with the idea of an immaterial essence, potentially dissociable from the biology of life and death.
\end{abstract}

\section{Keywords}

Dualism, soul, religious concepts

A 2006 article in US News \& World Report (Tolson, 2006) posed the question whether there is room for the soul in science. The article outlined various research programs occurring within the neurosciences exploring where and how consciousness might be situated within the brain. As stated by one researcher, this program of research has important ethical applications: "How do you understand consciousness well enough, how do you understand the self and identity well enough, to determine at what point a person is no longer in possession of a self, is no longer conscious in the way we would suggest others are conscious and have an identity" (Dial, as cited in Tolson, 2006, p. 6)? As is evident from the tenor of this quote, regardless of whether neuroscientists are able to prove or disprove the existence of the soul, the concepts 
of identity, consciousness and soul are deeply intertwined in human cognition about other humans. In fact, psychologists have argued that the concept of the soul is pervasive and inextinguishable because of basic, human, adaptive and cognitive processes (Bloom, 2004).

The concept of the soul, or something similar, is present in the major world religions; and evidence of similar concepts is present in several languages (Richert and Harris, 2006). Given the prevalence of this concept in human cultures, various researchers have explored its basis. One possibility is that the soul is a byproduct of a natural human tendency toward dualism, or the belief that mental states are distinct from bodily states. According to this hypothesis, the concept of the soul would be closely related to the concept of the mind. For example, Bloom (2004) has suggested that human infants are born with the tendency toward distinguishing animacy from inanimacy, and eventually conceptualize people in a dualistic fashion as consisting of separate, albeit interdependent, bodies and minds. A plausible extension of this theory is that the set of "mind" traits that infants attribute to humans, eventually, especially in religious circles, comes to be called the "soul".

Bering (2006) has claimed that the idea of psychological immortality is a default cognitive assumption. Thus, he argues that children and adults have difficulty in conceptualizing the complete cessation of psychological process at death. For example, in a study by Bering and Bjorklund (2004), adults and children saw a puppet show in which a mouse was eaten by an alligator. Even the youngest children understood that the mouse no longer had biological capabilities. However, both children and adults were likely to claim that the dead mouse still experienced psychological states like emotions, desires and thoughts. These findings imply that people assume that there is a close link between mental processes and the immortality of the soul.

An alternative position is that the concept of the soul is differentiated from a concept of the mind on the one hand and the body on the other. Two recent studies offer preliminary support for this proposal. Astuti and Harris (in press) found that Vezo children and adults in rural Madagascar were more likely to attribute continued functioning after death to those processes that were the focus of the afterlife beliefs in the culture, rather than to mental processes in general. More specifically, the Vezo believe that after death an individual becomes an ancestor and continues to influence the lives of his or her descendents. Participants were more likely to say that a dead individual would know his wife's name, remember where his house was, and miss his children than that he would see things, hear people and feel hungry. Second, Richert and Harris (2006) examined whether children aged 4 to 12 years think that the soul is the same thing as the mind. Using an adaptation of Johnson and Wellman's (1998) paradigm, children were invited to imagine that a baby's brain, 
mind, or soul had been magically removed and asked whether the baby could still perform certain functions. Most children claimed that the soul was not important for cognitive, non-cognitive, or behavioral functioning. When asked open-ended questions about what the soul does, children of all ages tended to argue that the soul has primarily spiritual functions. In addition, all children claimed that the soul was the aspect of identity most affected by a "spiritual act" (e.g., a ritual). More specifically, most children claimed that baptism changes a baby's soul whereas many fewer claimed that it changes the mind or brain. Thus, regardless of age or task, young children distinguished the functions of the soul from those of the mind.

The present study examines how Western adults conceive of the soul. Adults were the target for this study because the kinds of functions that participants attribute to the soul may be based on religious acculturation, a factor that may be less evident among children. Undergraduate participants were asked about their religious background, their belief in the existence of the soul, and their ideas about what the soul is. In addition, they were questioned about several moral issues that are likely to be related to the concept of the soul.

\section{Experiment}

\section{Method}

Participants. Participants were 161 undergraduate psychology students at a public university in southern California. The mean age of participants was 19 years $(\mathrm{SD}=3.69$; range $=17$ to $51 ; 70$ male, 91 female). The ethnic diversity of the sample reflects the ethnic diversity of the university $(43.5 \%$ Asian, 27.3\% Latino/Hispanic, 13.7\% Caucasian, 5.6\% African American and $9.9 \%$ other). There was also religious diversity in the sample of participants: $46.8 \%$ reported affiliation with either Protestant or Catholic denominations of Christianity, $19.9 \%$ of the participants reported no religious affiliation, 6.2\% were Buddhist, 2.5\% were Hindi, 1.9\% were Muslim, 1.9\% were Jewish and $1.9 \%$ affiliated with the Church of Jesus Christ of Latter Day Saints. As part of their Introduction to Psychology class, participants were required to complete research hours, and so received credit toward their class for completing the survey.

Procedure. Participants completed the survey online through the research participation system at the university. They were asked a series of questions about their beliefs concerning the mind and the soul. They were also asked to report their impressions of other people's beliefs about the same questions. 
Demographic Information. Participants were asked to report their age, gender and ethnicity. In addition, they were asked how strongly they were affiliated with a religious community (not at all, loosely, strongly), with which community they were affiliated, and how spiritual they considered themselves to be (not at all, somewhat, very). If participants indicated that they were not at all affiliated with a religious community or not at all spiritual, they received a score of 0 . If they responded that they were loosely affiliated with a religious community or somewhat spiritual, they received a score of 1 . If they responded that they were strongly affiliated with a religious community or very spiritual, they received a score of 2 . Thus, strength of religious affiliation and strength of spirituality scores ranged from 0 to 2 . The demographic information for the sample is reported in the participants section above.

Ontological Questions. Participants were asked a series of four ontological questions about the mind and the soul. First, participants were asked whether they thought the mind and soul exist (no, not sure, yes). If participants responded that they did not think that the mind or soul existed, they received a score of 0 . If they responded that they were unsure, they received a score of 1 . If they responded that the mind or soul exists, they received a score of 2 . Thus, mind existence and soul existence scores ranged from 0 to 2, with a higher score reflecting a greater degree of certainty in existence.

Second, participants were asked when the mind and soul begin (prior to conception, at conception, during pregnancy, at birth, never). A response indicating prior to conception received a score of 1 , at conception received a score of 2 , during pregnancy received a score of 3 , at birth received a score of 4 , and never received a score of 5. Thus, mind begin and soul begin scores ranged from 1 to 5, with higher scores indicating a later starting point.

Third, participants were asked whether the mind and soul remains constant or changes and develops over time (is constant, not sure, develops). If participants indicated that the mind or the soul remained constant over a person's life, they received a score of 0 . If they indicated that they were not sure, they received a score of 1 ; and if they claimed that the mind or soul change and develop over a person's life, they received a score of 2 . Thus, mind change and soul change scored ranged from 0 to 2 , with higher scores indicating belief in change.

Fourth, participants were asked what happens to the mind and soul at death (nothing, ceases to exist, continues on in an afterlife, continues on in reincarnation). If participants responded either that nothing happens or the mind and soul cease to exist, they received a score of 0 . If they responded that the mind or soul continues on in some way (either through an afterlife or reincar- 
nation), they received a score of 1 . Thus, mind death and soul death scores were either 0 or 1 , with a score of 1 indicating some form of continuation.

Functional Questions. To explore participants' beliefs about the functions of the mind and the soul, participants were asked to imagine that they lost their mind or their soul but continued on in some way. They were then asked to identify which of the following they would have lost: "my ability to solve problems", "my ability to think", "my ability to distinguish right from wrong", "my life force", "my ability to continue on after I die", "my ability to remember", "my ability to connect to a higher power", "my spiritual essence", "my ability to feel emotion" and "my ability to reason".

If participants responded that they would not have lost a particular ability, they received a score of 0 . If they responded that they were unsure, they received a score of 1 . If they responded that they would have lost the ability, they received a score of 2 . Thus, the score for each ability ranged from 0 to 2 , with higher scores indicating greater certainty of losing that ability.

Ethical questions. In the last part of the survey participants were asked to consider three ethical issues: stem cell research, disconnecting people from life support and human cloning. First, in the questions about stem cell research, participants were asked whether they believe an embryo has a mind and a soul and whether scientists should be allowed to use embryos for stem cell research. In each case, if participants responded no, they received a score of 0 . If they responded not sure, they received a score of 1 ; and if they responded yes, they received a score of 2 . Thus, embryo mind, embryo soul and stem cell research scores ranged from 0 to 2, with higher scores indicating a greater degree of certainty either in the existence of minds and souls in embryos or in allowing embryos to be used for stem cell research.

Second, in the questions about disconnecting people from life support, participants were asked whether they believe a person in a persistent vegetative state (PVS) has a mind and a soul and whether we should disconnect people who are in a PVS from life support. As with the scoring above, if participants responded no, they received a score of 0 . If they responded not sure, they received a score of 1 ; and if they responded yes, they received a score of 2 . Thus, PVS mind, PVS soul and PVS disconnect scores ranged from 0 to 2, with higher scores indicating a greater degree of certainty either in the continued existence of minds and souls in people in a PVS or in disconnecting people from life support.

Third, in the questions about human cloning, participants were asked whether they believe a human clone has a mind and a soul and whether scientists 
should be allowed to make human clones. As with the two other ethical questions, if participants responded no, they received a score of 0 . If they responded not sure, they received a score of 1 ; and if they responded yes, they received a score of 2. Thus clone mind, clone soul and cloning scores ranged from 0 to 2 , with higher scores indicating a greater degree of certainty either in the existence of minds and souls in human clones or in allowing the creation of human clones.

\section{Results}

\section{Ontological Questions}

As reported above, ordinal mind existence and soul existence scores ranging from 0 to 2 were computed based on participants' certainty about the existence of either the mind or the soul. A Wilcoxon Signed Ranks Test confirmed that there was a significant difference in the mind existence and soul existence scores, $Z=5.97, P<0.001$. More specifically, participants were less certain about the existence of the soul than the existence of the mind. With regard to the mind, $93.8 \%(n=151)$ of participants claimed that the mind exists, but only $66.5 \%$ $(n=107)$ claimed that the soul exists. An additional $28.6 \%(n=46)$ of participants were uncertain about the existence of the soul, but only $3.7 \%(n=6)$ of the participants were uncertain about whether the mind exists. Very few participants denied the existence of the mind, $2.5 \%(n=4)$, or the soul $5.0 \%$ $(n=8)$. Thus, almost all participants reported a belief in the existence of the soul as well as the mind, but they were more certain about the existence of the mind.

Participants were also asked when they thought the soul and the mind begin. The percentage of participants providing each response is recorded in Table 1. A Wilcoxon Signed Ranks Test was conducted on responses to the soul begin and mind begin questions, which had been scored ordinally from 1 ("prior to conception") to 5 ("never"). There was a significant difference in participants' claims about when the soul and mind begin, $Z=2.72, P<0.01$. Participants were more likely to claim that the soul begins earlier: $26.1 \%$ claimed that the soul begins "prior to conception" compared to only $8.1 \%$ of participants who claimed that the mind begins prior to conception. Equal numbers of participants claimed that the mind and soul begin "at conception" ( soul $=27.3 \%$, mind $=26.1 \%$ ). In contrast, participants were more likely to claim that the mind, rather than the soul, begins at some point "during pregnancy" $($ soul $=12.4 \%$, mind $=35.4 \%)$. 


\section{Table 1}

Percentage of participants giving each "soul begin" and "mind begin" response

\begin{tabular}{lccccc}
\hline & Never & $\begin{array}{c}\text { Prior to } \\
\text { conception }\end{array}$ & At conception & $\begin{array}{c}\text { During } \\
\text { pregnancy }\end{array}$ & At birth \\
\hline Mind & $1.2 \%$ & $8.1 \%$ & $26.1 \%$ & $35.4 \%$ & $29.2 \%$ \\
Soul & $5.6 \%$ & $26.1 \%$ & $27.3 \%$ & $12.4 \%$ & $28.6 \%$ \\
\hline
\end{tabular}

A Sign Test further confirmed that participants treated the mind and the soul differently, $Z=2.88, P<0.01$. More specifically, $45 \%(n=73)$ of the participants claimed that the soul and mind begin at the same time. In contrast, $36 \%$ $(n=58)$ of the participants claimed the soul begins before the mind; and $19 \%$ $(n=30)$ claimed the mind begins before the soul. In sum, participants expressed a variety of views about when the mind and the soul begin. Nevertheless, there was a systematic tendency to claim the soul begins before the mind.

Next, participants' responses to what happens to the mind and soul over the lifespan were compared. Mind change and soul change responses were scored ordinally, ranging from 0 ("is constant") to 2 ("develops over time"). Again, a Wilcoxon Signed Ranks test confirmed different patterns of responding for the mind change and soul change questions, $Z=6.59, P<0.001$. The vast majority of participants claimed that the mind changes over time $(86.3 \%)$; few claimed to be unsure $(9.4 \%)$ or claimed that the mind stays constant (4.4\%). In contrast, approximately half $(51.6 \%)$ claimed that the soul changes, $20.4 \%$ were unsure and $28.0 \%$ claimed that the soul stays constant. Thus, participants expected change for both the soul and the mind, but this expectation was more widespread for the mind.

Finally, participants' responses to mind death and soul death questions were compared to explore whether participants believe different things happen to the mind and soul at death. In this case, scores were nominal, with a score of 0 indicating that nothing happened or that the mind or soul ceases to exists, and a score of 1 indicating continuation of some kind. A McNemar Test revealed a significant difference in responding, $\chi^{2}(3, n=161)=80.52, p=0.000$. Most participants claimed that the mind ceases to exist at death (70.8\%); only a minority (29.2\%) asserted its continued existence. In contrast, most participants claimed that the soul continues on in some way (83.9\%); only a minority (16.1\%) claimed that the soul ceases to exist at death.

Summarizing across the four ontology questions, most participants asserted the mind's existence. They typically claimed that it begins at conception or later, changes in the course of development and ceases to function at death. Participants expressed more doubt about the existence of the soul as compared 
to the mind, were more likely to assert its existence prior to conception, its constancy throughout development and its existence beyond death. Thus, some if not all participants conceptualized the mind and the soul differently. A similar pattern emerged for participants' replies to functional questions, as described in the next section.

\section{Functional Questions}

As outlined above, participants were asked a series of questions intended to clarify their views about the functions of the soul and the mind. Participants were asked to imagine losing their soul or mind and to say whether they would have lost each of 10 different abilities as a result. To explore whether these 10 abilities could be grouped into different factors, Principle Components Analyses with Varimax rotations were conducted separately on the soul and mind ratings for each ability. Two factors emerged in both cases: Spiritual (life force, afterlife, connection to higher power, spiritual essence) and Cognitive (solve problems, think, tell right from wrong, remember). Emotion and reason loaded strongly on both factors, so they were not included with either factor.

Given that these different abilities grouped together to form two distinctive factors, four scores were computed for participants' ratings of each of the two functions of mind and soul: mind cognitive, mind spiritual, soul cognitive and soul spiritual. Scores were computed by tallying individual ratings ( 0 to 2 ) for each of the four abilities in that factor, resulting in the potential range of 0 to 8 . The means and standard deviations for each of these scores are portrayed in Fig. 1.

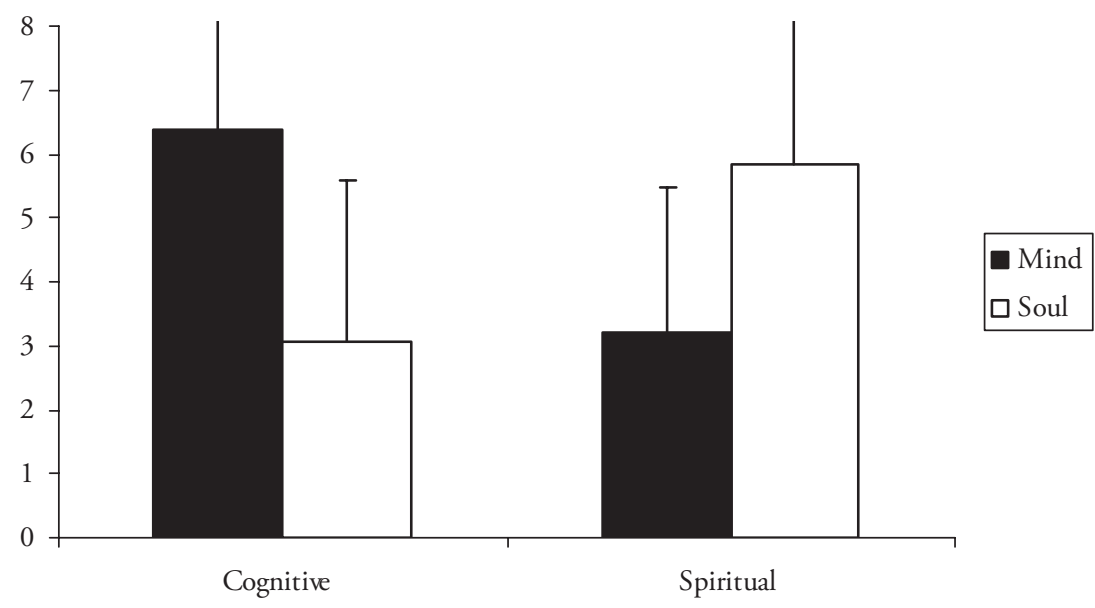

Figure 1. Means and standard deviations of function scores. 
An ANOVA was conducted with Entity (mind vs. soul) and Function (cognitive $v$ s. spiritual) as the within subjects variables. Results revealed a main effect of Entity, $F(1,155)=4.72, P<0.05$. In general, participants attributed more functions to the mind $(M=4.80, \mathrm{SE}=0.14)$ than to the soul $(M=4.44$, $\mathrm{SE}=0.16)$. There was also a trend toward a main effect of Function, $F(1,155)=$ $3.19, p=0.07$. Participants were more likely to attribute cognitive functions $(M=4.75, \mathrm{SE}=0.14)$ than spiritual functions $(M=4.49, \mathrm{SE}=0.14)$. Last, and most important, there was a highly significant Entity $\times$ Function interaction, $F(1,155)=242.07, p=0.000$. As is evident in Fig. 1, this interaction was caused by the tendency to attribute more cognitive functions to the mind $(M=6.43, \mathrm{SE}=0.18)$ than to the soul $(M=3.17, \mathrm{SE}=0.20)$ and more spiritual functions to the soul $(M=5.81, \mathrm{SE}=0.18)$ than the mind $(M=3.07$, $\mathrm{SE}=0.21$.

Table 2 indicates participants' responses to whether they would have lost the ability to have emotions or to reason following the loss of the soul or the mind. A Wilcoxon Signed Ranks test confirmed different patterns of responding for the mind reason and soul reason questions, $Z=3.93, P<0.001$. As is evident in Table 2, more participants claimed that they could no longer reason if they lost their mind than if they lost their soul. In contrast, there was no significant difference for mind emotion and soul emotion questions.

Table 2

Percentage of participants giving each response about reason and emotion

\begin{tabular}{lcccccc}
\hline & \multicolumn{3}{c}{ Reason } & \multicolumn{3}{c}{ Emotion } \\
& No & Not Sure & Yes & No & Not Sure & Yes \\
\hline Mind & $31.1 \%$ & $21.7 \%$ & $42.2 \%$ & $24.2 \%$ & $34.8 \%$ & $41.0 \%$ \\
Soul & $42.9 \%$ & $31.1 \%$ & $26.1 \%$ & $29.8 \%$ & $24.8 \%$ & $45.3 \%$ \\
\hline
\end{tabular}

In summary, as with the ontological distinction between soul and mind, participants also distinguished between the soul and the mind based on function. Participants were more likely to attribute a cluster of cognitive functions (solve problems, think, tell right from wrong, remember) to the mind as compared to the soul. They were more likely to attribute a cluster of spiritual functions (life force, afterlife, connection to a higher power, spiritual essence) to the soul as compared to the mind. Two other functions (reason and emotion) showed no clear association with either the cognitive or the spiritual cluster. Nevertheless, follow-up tests showed that reason was more closely associated with the mind than the soul. 


\section{Soul Spirituality vs. Mind Spirituality}

In order to further compare the relationship participants' concepts of the mind and the soul, two variables were created. The soul spirituality and mind spirituality scores were computed from participants' responses to the ontological and functional questions. To create each score, participants were given 1 point each if they claimed the mind or soul (a) exists before birth, (b) does not change, (c) survives death, (d) contributes to a person's life force, (e) contributes to a person's ability to live on after they die, (f) contributes to a person's ability to connect to a higher power and (g) contributes to a person's spiritual essence. Each score could range from 0 to 7 . A Paired-Samples $t$-test indicated that the mean soul spirituality score $(M=3.82, \mathrm{SD}=1.87)$ was significantly higher than the mind spirituality score $(M=1.39, \mathrm{SD}=1.50 ; t(160)=14.51$, $P<0.001)$.

Based on these scores, it is clear that, on average, participants rated the soul as being more spiritual than the mind. However, these findings do not tell us whether individual participants distinguished the soul from the mind. To compare individual responses, each participant's mind spirituality score was subtracted from his or her soul spirituality score. As is evident from Table 3, the majority $(83 \%)$ of participants attributed at least one more spiritual component to the soul than the mind; and a large proportion (68\%) attributed two or more. In contrast, only $5 \%$ of participants attributed two or more spiritual components to the mind than the soul.

Table 3

Percent of participants giving different spirituality ratings for the mind and the soul

\begin{tabular}{ccccc}
\hline $\begin{array}{c}2+\text { More for } \\
\text { Mind }\end{array}$ & $\begin{array}{c}1 \text { More for } \\
\text { Mind }\end{array}$ & Same & $\begin{array}{c}1 \text { More for } \\
\text { Soul }\end{array}$ & $\begin{array}{c}2+\text { More for } \\
\text { Soul }\end{array}$ \\
\hline $5 \%$ & $3 \%$ & $9 \%$ & $15 \%$ & $68 \%$ \\
\hline
\end{tabular}

The analyses up to this point show that participants differentiated the soul from the mind along a variety of dimensions related to each entity's ontology and function. In addition, rather than mean differences being accounted for by a small minority of participants considering the soul to be more spiritual while the majority considered the mind and soul to be equivalent, the majority of participants attributed more spiritual attributes to the soul than to the mind. 


\section{Ethical Questions}

As stated above, in the final portion of the survey, participants were asked their opinions about three ethical issues.

Stem cell research. In the first set of questions, participants were asked about stem cell research. The first of these questions asked participants whether they believed that an embryo has a mind or a soul. Responses were coded ordinally, and a Wilcoxon Signed Ranks test was conducted comparing responses about the mind and the soul. Participants were more likely to say that an embryo has a soul than a mind, $Z=3.30, P<0.001$. When asked whether an embryo has a soul, $39.1 \%$ of participants said "yes", $31.1 \%$ said "no" and the remaining $29.8 \%$ said that they were unsure. In contrast, when asked about whether an embryo has a mind, $29.2 \%$ said "yes", $43.5 \%$ of participants said "no" and $27.3 \%$ said they were unsure. Thus, participants were more likely to deny that an embryo has a mind than a soul. Participants were then asked whether they believe embryos should be used for stem cell research; $40.4 \%$ said "no", $33.5 \%$ said they were not sure and $26.1 \%$ said "yes".

Life support. In the second set of questions, students were asked about disconnecting people from life support. As with the embryo questions, the first of these questions asked participants whether they believed that a person in a persistent vegetative state (PVS) has a mind or a soul. Responses were coded ordinally, and a Wilcoxon Signed Ranks test was conducted comparing responses about the mind and the soul. Participants were more likely to say that a person with PVS has a soul than a mind, $Z=68.25, P<0.001$. When asked whether a person with PVS has a soul, $80.1 \%$ of participants said "yes", $14.9 \%$ said they were unsure and only 5.0\% said "no". In contrast, only $32.9 \%$ of participants claimed that a person with PVS has a mind, $27.3 \%$ said they were unsure and the remaining $40.4 \%$ of participants said that a person with PVS does not have a mind. Participants were then asked whether we should disconnect people with PVS from life support. In this case, $40.4 \%$ of participants said we should disconnect life support, $22.4 \%$ said we should not disconnect from life support and the remaining $37.3 \%$ of participants said they were unsure.

Human cloning. In the third set of questions, participants were asked about human cloning. As with the embryo and life support questions, the first of these questions asked participants whether they believed that a human clone has a mind or a soul. Responses were coded ordinally, and a Wilcoxon Signed Ranks test was conducted comparing responses about the mind and the soul. 
Participants were more likely to say that a clone has a mind than a soul, $Z=6.62, p<.001$. When asked whether clone has a soul, $32.2 \%$ of participants said "yes", $33.5 \%$ said "no" and the remaining $34.2 \%$ said that they were unsure. In contrast, $67.1 \%$ said that a clone has mind, $21.1 \%$ said they were unsure and only $11.8 \%$ of participants said that a clone does not have a mind. Next, participants were asked whether they believed that we should make human clones; $57.8 \%$ of participants said "no", $27.3 \%$ said they were unsure and $14.9 \%$ said "yes".

Predictive analyses. In order to explore the effect that people's concepts of the soul and the mind have on their ethical beliefs, the soul spirituality and mind spirituality scores, computed from participants' responses to the ontological and functional questions, were used as predictors of participants' responses to the ethical questions. An additional variable, an ethics total score, was computed by summing participants' responses to the three ethical questions. This variable was computed because Pearson Correlations indicated that all responses were significantly correlated. The correlations are listed in Table 4.

\section{Table 4}

Correlations between participants' responses to ethical questions

Stem cell research? Disconnect life Human clones? support?

\begin{tabular}{|c|c|c|c|}
\hline Stem cell research? & 1.00 & $0.252^{* *}$ & $0.306^{* *}$ \\
\hline $\begin{array}{l}\text { Disconnect life } \\
\text { support? }\end{array}$ & & 1.00 & $0.136^{*}$ \\
\hline Human clones? & & & 1.00 \\
\hline
\end{tabular}

${ }^{* *} P<0.001,{ }^{*} P<0.1$.

In order to compute the ethics total score, each "no" response was coded 0 , each "not sure" response was coded 1, and each "yes" response was coded 2. These scores were tallied across the three ethical questions for a mean score of $2.61(\mathrm{SD}=1.61)$. To explore the relationship between the ethics total score and participants' concepts of the mind and soul, two regressions were conducted predicting the ethics total score from the soul spirituality and mind spirituality scores. Only the regression predicting ethics total from soul spirituality was significant, $r^{2}=0.08, \beta=-0.29, P<0.001$.

In order to explore the potential confound with religious affiliation, a second regression was conducted predicting ethics total from soul spirituality controlling for participants' strength of religious affiliation. This regression was also 
significant, $r^{2}=0.19, P<0.001$; and strength of religious affiliation emerged as a significant predictor of the ethics total score, $\beta=-0.36, P<0.001$. Even after controlling for strength of religious affiliation, there was a near-significant trend for soul spirituality to be a predictor of ethics total, $\beta=-0.15, P=0.06$.

In summary, participants' concept of the soul was related to their responses to ethical questions. In particular, the more "spiritual" that participants considered the soul to be, the less likely they were to agree with using embryos for stem cell research, disconnecting people from life support and human cloning. Participants who expressed a more spiritual concept of the soul were likely to report a strong religious affiliation. These relationships did not exist between people's concepts of the mind and their responses to ethical questions.

\section{Discussion}

In order to examine whether adults conceive of the mind and soul differently, participants were asked about the existence and function of each. In addition, potential links between participants' mind and soul concepts and their ethical views were probed. Participants generally offered a secular view of the mind. Although almost everyone said that the mind exists, very few claimed that its existence antedates the moment of conception, that it remains invariant over the lifespan, or that it survives death. Instead, most participants appeared to conceptualize the mind in relation to the human lifecycle, constrained by the biological cycle of conception, growth and death. Further evidence for this secular conception of the mind emerged in participants' replies to the functional questions. They conceived of the mind primarily as a cognitive organ, dedicated to problem solving, thinking, judging and remembering.

By contrast, the soul was more often conceptualized in spiritual terms. Although over one quarter of the participants were uncertain of its existence, more than half said that it comes into existence at or before the moment of conception and most claimed that it survives death. Moreover, a sizable minority of participants said that the soul remains invariant over the lifecycle, a response that was very rarely offered for the mind. Thus, participants often dissociated the existence of the soul from the cycle of conception, growth and death. They conceived of it as a more constant entity, sometimes existing before the moment of conception and often persisting beyond death. Participants' spiritual conception of the soul was also apparent when they replied to the functional questions. They did not construe the functions of the soul in narrowly cognitive terms but often linked it to various spiritual powers or processes.

A more inclusive analysis of participants' replies across various questions further confirmed that mind and soul are differentiated. Recall that participants 
were scored on a total of 7 questions for any reply that indexed a spiritual perspective. Overall, this perspective was voiced much more frequently for the soul than for the mind. In addition, when the pattern of replies for individual participants was examined, a large majority $(93.7 \%)$ of participants displayed more than one spiritual response for the soul, whereas only a minority $(36.0 \%)$ did so for the mind.

Taken together, these findings indicate that most participants do not adopt a simple, dualist stance. According to dualism, human beings are composed of two different types of process: mental processes, on the one hand, and bodily processes, on the other. As noted in the introduction, some authors have proposed that an early tendency toward dualism underpins a belief in the afterlife because dualism implies the possibility of a separate and potentially autonomous existence for mental processes, even after the cessation of bodily processes. The present findings cast doubt on this proposal. Most participants are not simple dualists. They have concepts of both the mind and the soul, and they conceptualize these two entities differently. Participants who entertain both concepts associate the afterlife with the soul, but they generally link the mind to the human lifecycle. Thus, participants view the soul as having a temporal span that can be disconnected from the body whereas they judge the temporal span of the mind to be similar to that of the body.

What is the basis for adults' concept of the soul? Arguably, two factors play a mutually-supportive role. First, it is plausible that people think of human beings as having an invariant essence that confers a stable identity despite the various transformations brought about by the processes of growth and ageing. To the extent that this essence is preserved despite those transformations, it may be feasible to imagine its existence independent of that biological cycle. On this view, the human lifecycle is no more than the temporary embodiment of something more permanent. Gelman (2003) has shown that children are disposed to such essentialist thinking when they reflect on the identity of various natural kinds, both animate and inanimate. Thus, it is plausible that essentialist thinking also plays a role when children reflect on the ontology of human beings.

A second factor, distinct from but potentially operating in concert with the first, is exposure to everyday discourse. It is plausible that many participants hear remarks linking the soul to spiritual as opposed to secular concerns. For example, participants are likely to hear references to "immortal souls", to God's power to "save" souls, and to the link between the soul and the unique or core features of a being or entity (i.e., "the very soul..."). Thus, discourse about the soul is likely to support the belief that human beings are endowed with a stable, enduring identity having unique spiritual or divine elements. 
More generally, it is plausible to suppose that an early-emerging disposition toward essentialist thinking about human beings is sustained by exposure to discourse linking that essence to God, the afterlife, and an individual's unique characteristics. Note that everyday discourse is unlikely to play such a role for conceptions of the mind. We do not ordinarily speak of "immortal minds", or of God's power to "save" minds. Moreover, we ordinarily assume that people retain their individual identity in the face of major disturbances to their cognitive functioning, as in the case of psychosis, dementia, or long-term disturbances to consciousness (as in PVS).

A final point for consideration is the extent to which participants' beliefs about the soul influenced their ethical decision making. Recall that participants who expressed a more "spiritual" conception of the soul were less likely to agree with using embryos for stem cell research, disconnecting people from life support, and human cloning. In contrast, there was no relationship between people's "spiritual" conception of the mind and their responses to ethical questions.

The strength of participants' religious affiliation also predicted their ethical decision making. Indeed, much research has addressed the strong relationship between people's religious background and their decisions about ethical or political issues (see review in Donahue and Nielsen, 2005). The more intriguing finding was that people's concepts of the soul predicted their ethical decision making independently of religious affiliation. This finding suggests that religious affiliation alone may not fully account for people's decisions regarding "moral issues". Recall that many voters in the 2004 Presidential election claimed they voted for President Bush based on "moral issues", such as embryonic stem-cell research, gay marriage, abortion and immigration; and these voting patterns have generally been linked to voters' religious affiliation (Denton, 2005).

Our findings raise the possibility that people's decisions about ethical and political issues may not simply reflect a particular religious doctrine, but may be based on a more general conception of personal identity. Although religious doctrine and everyday concepts often coincide with each other, they are not necessarily identical. Thus, not all people from the same religious backgrounds have the same beliefs about the soul; and many people who claim no religious affiliation at all have beliefs about the soul that are similar to those with religious beliefs. Further research into the impact of religious affiliation and spiritual concepts on decision making should seek to differentiate the concepts themselves from their doctrinal contexts.

In conclusion, we may consider the extent to which the present findings may be generalized to other groups. It could be argued that the present results capture a culturally-specific distinction only, one found among respondents raised in English-speaking, Christian communities but not likely to be found 
elsewhere. Certainly, it is possible to argue that the pattern of results obtained is closely connected to participants' intuitions about two specific terms, namely "soul" and "mind".

However, an alternative possibility is worth considering. Consider two geographically-isolated, small-scale, traditional societies with no known history of contact or exchange - the Vezo of Western Madagascar and the Lohorung of Eastern Nepal. The Vezo distinguish three different aspects of a person: vata, say and fanahy (Astuti and Harris, in press). The term vata corresponds quite closely to the English term 'body'. The terms say and fanahy, in contrast, refer to noncorporeal aspects of the person.

People are attributed varying degrees of say. For example, someone who behaves oddly is said to have a sick say or to have lost his or her say; a person who is mentally handicapped is said not to have enough say; and children are credited with little say. On the other hand, a person who is wise is said to have say. Children use the term to tell someone that their say is insufficient, i.e., that they are stupid. Because say is used to explain variation in the capacity for intelligent or competent behavior, it can be tentatively translated as 'mind' (Astuti and Harris, in press).

The term fanahy is used to describe a person's social disposition. Generous people are said to have a beautiful or good fanahy whereas those who are easily angered or are mean are said to have a bad fanahy. Children attribute a good fanahy to their friends and a bad one to their enemies. The say and fanahy of any given individual can vary independently. For example, someone who has little say, can still have a good fanahy. Adults claim that when people are asleep the fanahy wanders around, detached from the body, and that when people die the fanahy leaves the body permanently. Thus, like the tern soul, the term fanaby is associated with the enduring, non-cognitive, and spiritual aspects of a person (Astuti and Harris, in press).

The Lohorung Rai of East Nepal differentiate a person's niwa from their lawa (Hardman, 2000). The concept of niwa corresponds roughly to the English concept of mind. The Lohorung think of niwa as slowly increasing in strength in the course of childhood. They invoke this changing strength to explain young children's lack of reflection as compared to the emerging sense of responsibility and awareness that is displayed by older children and adolescents. Similarly, the Lohorung attribute the forgetfulness of the elderly to fading of niwa. By contrast, a person's lawa comes to them when they are in the womb. It can sometimes leave the body during the person's lifetime, especially during dreams, but its permanent departure from the body is associated with death. 
The parallels between the Vezo and Lohorung conceptions of mental processes are striking. In particular, both languages differentiate between a reflective capacity that accounts for variation in judgment and competence and a spiritual core that is potentially dissociable from the body. Given these parallels, it is worth entertaining the possibility that such a distinction is not tied to Christian or Western traditions alone but is widespread, if not universal. Barrett and Richert (2003) have argued that the human mind has evolved to be "cognitively prepared" to receive supernatural or religious concepts. Similarily, Bering (2006) has argued that "the standard architecture of ancestral human minds was co-opted by natural selection to create the functional illusion of an intelligently designed, immortal soul" (p. 461). Considered in this light, the findings of a pervasive mind/soul distinction may provide further evidence for arguments about the universality of some religious concepts.

\section{References}

Astuti, R. and Harris, P. L. (in press). Understanding mortality and the life of the ancestors in rural Madagascar. Cognitive Science.

Barrett, J. L. and Richert, R. A. (2003). Anthropomorphism or preparedness? Exploring children's God concepts. Review of Religious Research 44, 300-312.

Bering, J. M. (2006). The folk psychology of souls. Brain and Behavioral Sciences 29, 453-462.

Bering, J. M. and Bjorklund, D. F. (2004). The natural emergence of reasoning about the afterlife as a developmental regularity. Developmental Psychology 40, 217-233.

Bloom, P. (2004). Descartes' baby: How the science of child development explains what makes us human. Basic Books, New York, NY.

Denton Jr., R. E. (2005). Religions and the 2004 Presidential campaign. American Behavioral Scientist 49, 11-31.

Donahue, M. J. and Nielsen, M. E. (2005). Religion, attitudes, and social behavior, in R. F. Paloutzian and C. L. Park (Eds.), Handbook of the psychology of religion and spirituality, pp. 274-291. Guilford, New York, NY.

Gelman, S. A. (2003). The essential child: Origins of essentialism in everyday thought. Oxford University Press, New York, NY.

Hardman, C. E. (2000). Other worlds: Notions of self and emotion among the Lohorung Rai. Berg, Oxford.

Johnson, C. N. and Wellman, H. M. (1982). Children's developing conceptions of the mind and brain. Child Development 53, 222-234.

Richert, R. A. and Harris, P. L. (2006). The ghost in my body: Children's developing concept of the soul. Journal of Cognition and Culture 6, 409-427.

Tolson, J. (2006). Is there room for the soul? [Electronic version]. US News and World Report. Retrieved July 11, 2007, from http://health.usnews.com/usnews/health/articles/061015/23 soul.htm. 